\title{
Characterisation of a Helicobacter pylori phage (HP1)
}

\author{
EVELYN HEINTSCHEL VON HEINEGG, H. P. NALIK and E. N. SCHMID
}

Institute for Medical Microbiology, University of Essen, Hufelandstr. 55, 4300 Essen 1, Germany

\begin{abstract}
Summary. The infection of two Helicobacter pylori strains with a phage-containing supernate of the lysogenic $H$. pylori strain IMMi 290/89 resulted in a lytic cycle and propagation of phage HP1. In negatively-stained preparations, the empty phage heads measured $55-60 \mathrm{~nm}$ in diameter and mature heads measured $50 \mathrm{~nm}$. The flexible, striated phage tail was $c .170 \mathrm{~nm}$ in length and $9.5 \mathrm{~nm}$ in diameter. The phage showed a mean density of $1.40 \mathrm{~g} / \mathrm{cm}^{3}$ in sucrosedensity gradients and contained double-stranded DNA $c .22000 \mathrm{bp}$ in length.
\end{abstract}

\section{Introduction}

The presence of intracellular bacteriophage-like particles in Helicobacter pylori present in biopsy specimens was first reported by Marshall et al. ${ }^{1}$ and Goodwin et al., ${ }^{2}$ but has since received only limited attention. More recently the isolation of an $H$. pylori strain (SchReck 290) that spontaneously produced bacteriophages in vitro was described by Schmid et al. ${ }^{3}$ The object of this study was the characterisation of the $H$. pylori phage HPl recovered from $H$. pylori strain SchReck 290, including its propagation and isolation, lytic cycle, morphology and genome composition.

\section{Materials and methods}

\section{H. pylori strains}

The $H$. pylori strain IMMi 290/89 designated SchReck was reported previously to contain bacteriophages. ${ }^{3}$ The strain was stored in brain-heart infusion broth containing glycerol $15 \%$ and sheep blood $20 \%$ for 1 year at $-80^{\circ} \mathrm{C}$.

Ten different clinical isolates of $H$. pylori (IMMi 733/89, IMMi 23/90, IMMi 31/90, IMMi 41/90, IMMi 42/90, IMMi 71/90, IMMi 75/90, IMMi 187/90, IMMi 188/90, IMMi 189/90) were chosen as indicator strains for the propagation of the phage. The strains were isolated from gastric biopsies from patients attending the Department of Gastroenterology of the University of Essen. The isolates showed the morphology typical of $H$. pylori and rapid urease, catalase and oxidase reactions.

\section{Growth conditions}

For permanent subculture the bacteria were grown on Sheep Blood Agar (SBA; CM 55, Oxoid), con- taining whole sheep blood (Oxoid) $10 \%{ }^{4}$ The plaque assay and the induction procedures were performed on SBA and on IsoSensitest Agar (Oxoid) supplemented with bovine serum albumin (Sigma, No. A 2153) 5\% (IBA). The broth cultures were performed with BrainHeart Infusion Broth (BHIB; CM 225, Oxoid) supplemented with calf serum 10\% (FKS; Serva 47900, Heidelberg, Germany) and yeast extract (Flow 30-00049, Meckenheim, Germany) $0.25 \%$ in $5-\mathrm{ml}$ volumes.

All incubation was done at $37^{\circ} \mathrm{C}$ in GasPak-jars (BBL, Cockeysville, MD, USA) in a micro-aerophilic atmosphere $\left(\mathrm{O}_{2} 5-7 \% \mathrm{v} / \mathrm{v}, \mathrm{CO}_{2} 8-10 \% \mathrm{v} / \mathrm{v}, \mathrm{N}_{2}\right.$ $83-87 \%$ v/v) (Anaerocult C, Merck, Germany).

\section{Propagation and isolation of the phage}

After cultivation on SBA the $10 \mathrm{H}$. pylori strains were harvested and suspended in BHIB to a density corresponding to McFarland turbidity standard No. 1. A volume of $100 \mu \mathrm{l}$ of the thawed and filtered phage-containing supernate of the $H$. pylori strain IMMi $290 / 89$ was added to the bacterial suspension.

After incubation for 3 days at $37^{\circ} \mathrm{C}$ the turbidity of the test samples was measured with a spectrophotometer (1101 M, Eppendorf, Germany) at $578 \mathrm{~nm}$ and compared with the uninfected controls; $200-\mu 1$ volumes of the suspensions were streaked out on sheep blood agar to estimate the decrease in viable count and to ensure purity of the remaining bacteria.

The broth cultures with lysed bacteria were centrifuged at $11000 \mathrm{~g}$ (JA 20.1 rotor, J2-21 centrifuge, Beckman, Palo Alto, USA) for $10 \mathrm{~min}$ to remove the bacterial debris. The phages in the supernate were sedimented through layers of sucrose $20 \%$ and $10 \%$ at $284000 \mathrm{~g}$ for $2 \mathrm{~h}$ according to McNaughton and Matthews $^{5}$ in a Beckman ultracentrifuge, and resuspended in $500 \mu \mathrm{l}$ of PBS. Volumes of $2 \mathrm{ml}$ were layered on to $10.5 \mathrm{ml}$ of pre-formed sucrose 5-60\% gradients prepared in PBS. The gradients were centrifuged in a Beckman SW 40 Ti rotor for $4 \mathrm{~h}$ at $250000 \mathrm{~g}$ at $5{ }^{\circ} \mathrm{C}$. Twenty $600-\mu \mathrm{l}$ gradient fractions were col- 

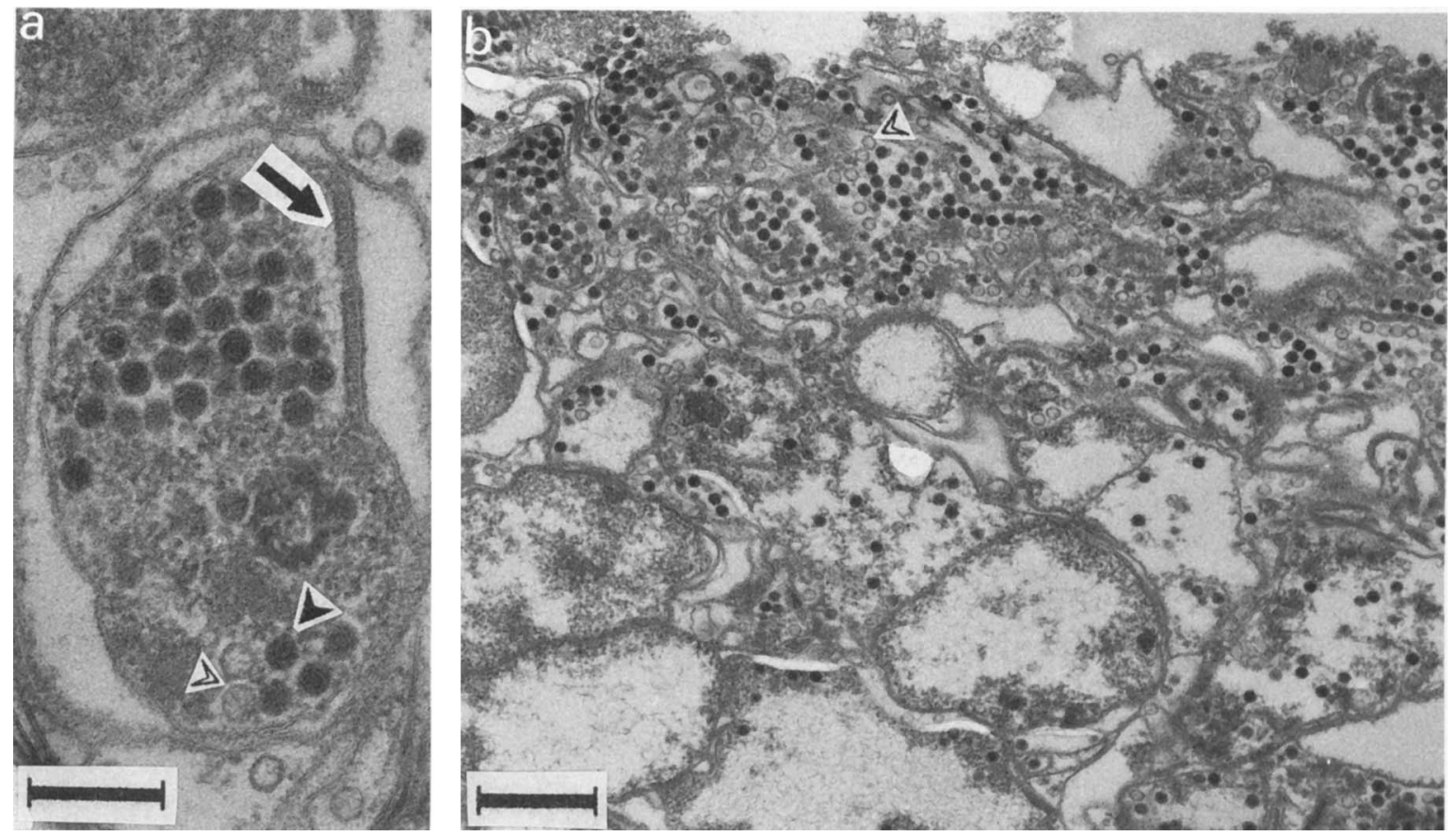

Figs. 1a and b. Transmission electronmicrograph of thin sections of agar plaques from $H$.pylori strain IMMi $42 / 90$ infected with phage HP1 isolated from broth cultures of infected $H$. pylori strain IMMi $42 / 90 ; \rightarrow$ indicates submembraneous complex typically found in $H$. pylori cells, $>$, $>$ indicate mature and empty phage heads, respectively. Bar $=$ (a) $200 \mathrm{~nm}$, (b) $500 \mathrm{~nm}$.

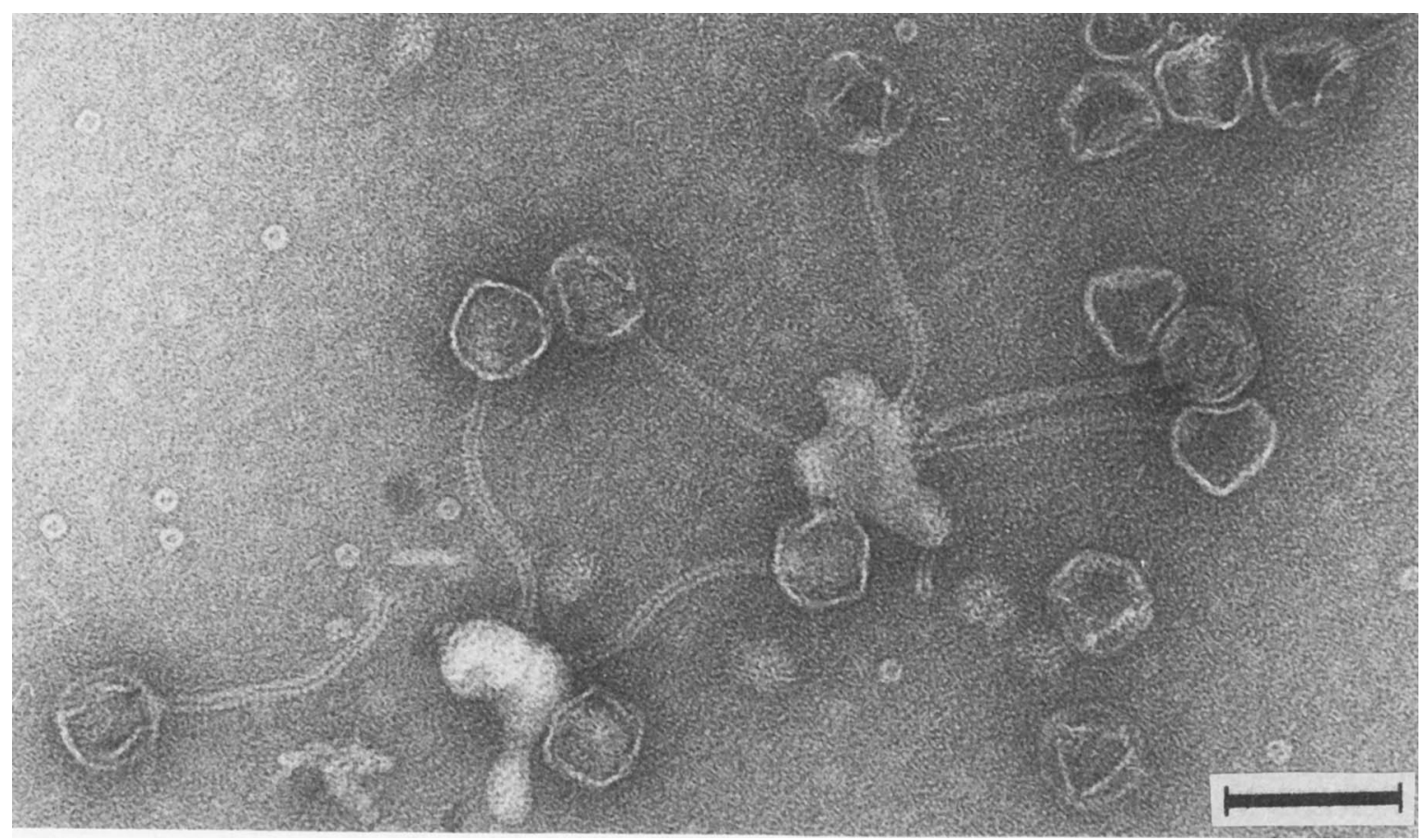

Fig. 2. Transmission electronmicrograph of negatively stained preparations of phage HP1 isolated from broth cultures of phage-infected $H$. pylori strain IMMi $42 / 90$. Bar $=100 \mathrm{~nm}$.

lected. The sucrose concentration of each fraction was determined with an Abbe-refractometer (Zeiss, Oberkochen, Germany). All steps of the phage isolation were monitored by electronmicroscopy.

\section{Plaque assay}

The plaque assay was performed by the single layer method. ${ }^{6}$ After cultivation for 3 days on SBA the $10 \mathrm{H}$. pylori strains were harvested and suspended in $5 \mathrm{ml}$ of
$\mathrm{NaCl} 0.9 \%$ to a density corresponding to MacFarland turbidity standard No. 10. One-ml volumes were poured on SBA and IBA and cultured at $37{ }^{\circ} \mathrm{C}$ in a micro-aerophilic atmosphere for $24 \mathrm{~h}$. Volumes of $5 \mu \mathrm{l}$ of the phage-containing sucrose-gradient-fractions of the infected $H$. pylori strain IMMi $42 / 90$, and $5 \mu$ l of PBS as a negative control, were spotted on the bacterial lawns and cultured for up to $72 \mathrm{~h}$. Examination of plates for plaques was done at 24-h intervals. 


\section{Induction methods}

Eight $H$. pylori strains (IMMi 733/89, IMMi 23/90, IMMi 31/90, IMMi 71/90, IMMi 75/90, IMMi 187/90, IMMi 188/90, IMMi 189/90) were not susceptible to lysis by HP1 and, therefore, were suspect for lysogeny. Before exposure to induction procedures bacteria were harvested from 3-day old cultures on SBA and suspended in $10 \mathrm{ml}$ of $\mathrm{NaCl} 0.9 \%$ to a density corresponding to MacFarland turbidity standard No. 10. For the mitomycin $\mathrm{C}$ assay and the ultraviolet irradiation, 1-ml volumes of the bacterial suspensions were streaked out on SBA and IBA and cultured for $24 \mathrm{~h}$ in a micro-aerophilic atmosphere. The mitomycin $\mathrm{C}$ assay was performed by placing disks of mitomycin $\mathrm{C}(1 \mu \mathrm{g})$ on the lawns of the $H$. pylori strains. ${ }^{7}$ Ultraviolet irradiation of the bacteria was done with an ultraviolet lamp (254 $\mathrm{nm}$ grid tube, $50 \mathrm{~W}$ input-power, Vl-50C, Bioblock Scientific, Illkirch, France) for $30 \mathrm{~s}, 60 \mathrm{~s}, 90 \mathrm{~s}$ and $120 \mathrm{~s}$ at a distance of $10 \mathrm{~cm}$. Induction by high temperature was performed by pre-incubating the bacterial suspensions in a water bath at $50^{\circ} \mathrm{C}$ for up to $10 \mathrm{~min} ; 0.5-\mathrm{ml}$ volumes were poured on SBA and IBA every minute. The bacteria were incubated for up to $72 \mathrm{~h}$ and monitored for plaques at 24 -h intervals.

\section{Electronmicroscopy}

For negative staining with uranyl acetate $2 \%$, samples were taken from the uncentrifuged broth cultures of $H$. pylori strains IMMi 41/90 and IMMi $42 / 90$ and the fractions after sucrose gradient centrifugation.

For thin sections, small squares of the plaques in the lawn of $H$. pylori strain IMMi 42/90 were immersed in $0.2 \mathrm{M}$ cacodylate buffer containing glutaraldehyde $2 \%$. After pre-fixation for $2 \mathrm{~h}$ at $4{ }^{\circ} \mathrm{C}$, the specimens were fixed in osmium tetroxide $1 \%$ followed by uranyl acetate $2 \%$. The fixed specimens were dehydrated in acetone 30, 50, 70, 90 and $100 \%$ and embedded in glycidether (Epon 812, Roth, Germany). The thin sections were stained with lead citrate $1 \%$ and screened with an EM 10 (Zeiss, Oberkochen, Germany).

\section{Preparation of bacteriophage DNA}

The phage DNA was isolated from $H$. pylori strain IMMi 41/90 uncentrifuged liquid culture. The bacterial nucleic acids as well as the plasmid DNA were digested with DNAase I (Serva, Heidelberg, Germany) $2 \mu \mathrm{g} / \mathrm{ml}$ and RNAase A (Boehringer, Mannheim, Germany) $4 \mu \mathrm{g} / \mathrm{ml}$. The phage DNA was prepared according to the method of Maniatis et al. ${ }^{8}$ The precipitation of the phage particles was performed in a polyethylene-glycol $10 \%$ solution omitting the $\mathrm{CsCl}$ gradient step. The nucleic acid of the phage was then treated with RNAase A for a second time to determine its sensitivity and to digest remaining bacterial RNA. The phage DNA was cleaved with the restriction endonuclease $E c o$ RI (Boehringer). After digestion the phage DNA was separated in a nondenaturing gel of agarose $1 \%$ with ethidium bromide as staining agent.

To estimate the length of the phage genome, the agarose gel was standardised with DNA-fragments of the plasmid pAT $153,{ }^{9}$ produced by a Hinf I and EcoRI digest.

\section{Results}

As the phage-containing $H$. pylori strain IMMi 290/89 could not be re-cultivated after storage for 1 year at $-80^{\circ} \mathrm{C}, 10 \mathrm{H}$. pylori strains were inoculated with the phage-containing supernate from the stored strain to identify potential host strains. After incubation for 3 days two of the 10 strains, IMMi 41/90 and IMMi 42/90, showed reduced opacity in the test preparations in comparison with

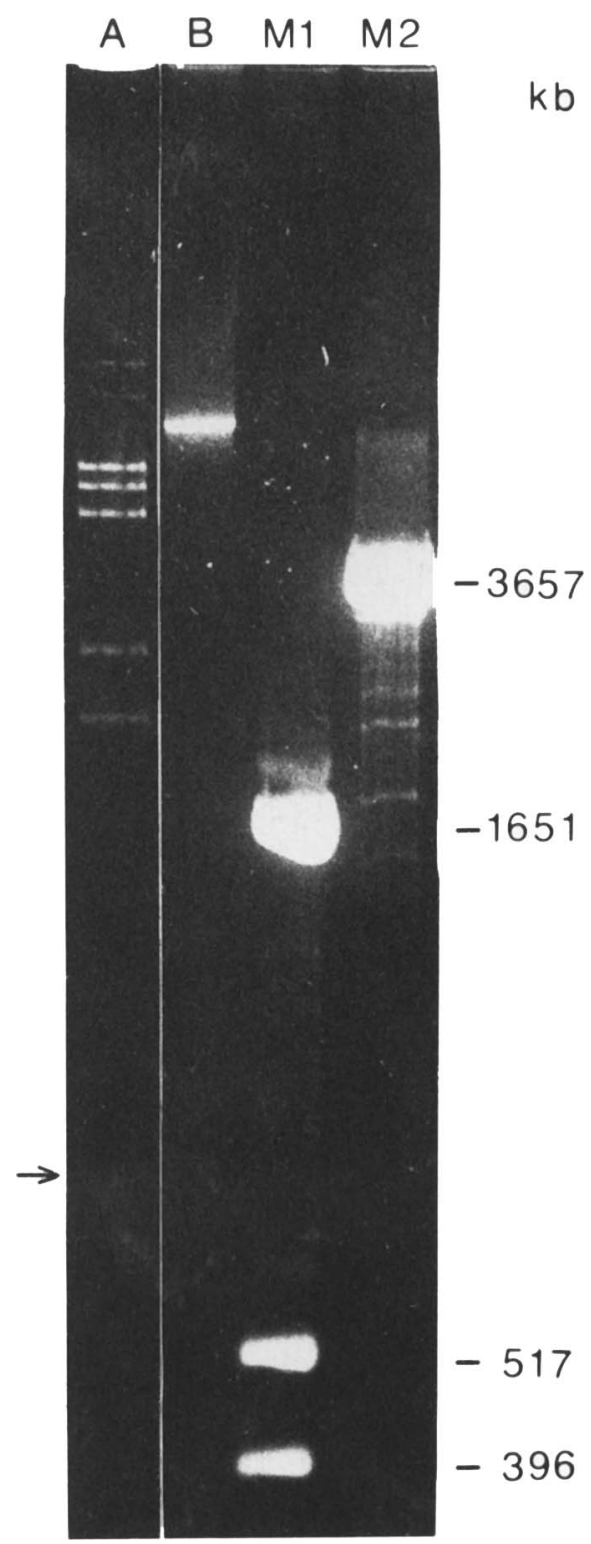

Fig. 3. Restriction endonuclease digest of DNA of phage HPI isolated from $H$. pylori strain IMMi 41/90. A, EcoRI digest; B, undigested HP1 DNA; M1, marker pat 153, Hinf1; M2, marker pat $153, E c o$ RI ; $\rightarrow$ indicates weakly stained fragment. 
control tubes. This was confirmed by subculture on SBA.

After incubation for 3 days on IBA, but not on SBA, a clear zone of lysis appeared in the lawn of $H$. pylori strain IMMi $42 / 90$ at the application points of the phage-containing sucrose-gradient fractions. No plaques were seen in the other $H$. pylori strains tested.

Eight $H$. pylori strains were immune or resistant to the phage HPl in the broth assay and in the plaque assay. Inducing systems, including mitomycin $\mathrm{C}$, ultraviolet irradiation or high temperature, did not show evidence of lysogeny in these strains.

In the epon-embedded samples of the plaques, phage heads with diameters of $c .60 \mathrm{~nm}$ were found in infected bacteria (figs. 1a and 1b). In negatively-stained preparations of both infected $H$. pylori strains, empty phage heads had diameters in the range $55-60 \mathrm{~nm}$ while mature heads measured $c .50 \mathrm{~nm}$. The flexible phage tail was about $170 \mathrm{~nm}$ in length and $9.5 \mathrm{~nm}$ in diameter (fig. 2).

Phage particles with a density of $c .1 .40 \mathrm{~g} / \mathrm{cm}^{3}$ were found in sucrose-gradient centrifugation.

Treatment of the isolated phage nucleic acid with RNAase A digested the remaining bacterial RNA but did not degrade the phage nucleic acid. However, the phage nucleic acid was digested with class II-restriction endonucleases (HaeIII, Hinf I and EcoRI) which digest only double-stranded DNA. Therefore the nucleic acid of the phage HP1 was identified as doublestranded DNA. After cleavage with restriction enzyme $E c o$ RI, the separation of the phage DNA in the standardised agarose gel resulted in six detectable fragments (sizes are shown in fig. 3). Addition of the fragment lengths resulted in $c .22000 \mathrm{bp}$ for the whole phage DNA.

\section{Discussion}

This report for the first time describes a lytic phage infection in $H$. pylori as a pre-condition for propagation and physical characterisation of the phage HP1. To classify this phage, the physical characteristics found in this study were compared with those of other phages. Phage HP1 showed several similarities to members of the family Syphoviridae which possess heads of $c .60 \mathrm{~nm}$ in diameter, a long non-contractile tail of $c .150 \mathrm{~nm}$ in length, a mean density of $1.49 \mathrm{~g} / \mathrm{cm}^{3}$ and double-stranded DNA with a length of $c$. $45-50 \mathrm{~kb}^{10}$

Our findings were compared with the information given in previous publications on the morphology of H. pylori phages. Thus Marshall et al. ${ }^{1}$ found intracellular bacteriophage-like particles as well as released,phages in $H$. pylori in two different gastric spes. mens. These icosahedral phages were of helical structure, without a tail, and measured c. $40 \mathrm{~nm}$ in diameter. Some of the phages were adjacent to remnants of lysed bacteria. Goodwin et al. ${ }^{2}$ also described tail-less intracellular bacteriophages of icosahedral structure and with diameters of $c .80-90 \mathrm{~nm}$ in $H$. pylori in a gastric biopsy. The first in-vitro study with more detailed information about a strain of $H$. pylori harbouring bacteriophage (SchReck, IMMi 290/89) was reported by Schmid et al. ${ }^{3}$ Thinsection electronmicrographs of this $H$. pylori strain revealed bacteria packed with empty and filled phage heads with dimensions of $c .70 \times 60 \mathrm{~nm}$, as well as lysed bacteria with released phages which possessed tails with a length of $120 \mathrm{~nm}$ that were adjacent to the bacterial cell wall. The negatively stained preparations of HP1 presented in this study reveal the same morphology as those described by Schmid et al. ${ }^{3}$ An explanation for the differences in bacteriophage sizes and morphology is that there are three apparently different morphotypes of $H$. pylori phages.

Several attempts have been made to differentiate subtypes of $H$. pylori. The most successful studies on the heterogeneity of $H$. pylori strains have been with restriction endonuclease analysis of chromosomal DNA, ${ }^{11,12}$ ribosomal RNA gene patterns ${ }^{13}$ and PCRamplified differentiation of the urease structural genes. ${ }^{14}$ These methods seem to provide reproducible methods for the identification of subtypes of $H$. pylori, although restriction endonuclease analysis of chromosomal DNA produced only minor differences in DNA patterns and was difficult to interpret. ${ }^{12}$ Plasmid analysis as a marker of differentiation of $H$. pylori strains ${ }^{15,16}$ seems to be less suitable, since only $19-50 \%$ of $H$. pylori strains carried plasmids, which may have been responsible for the minor differences in gene patterns. $^{12}$

Another approach, both to distinguish $H$. pylori isolates and to support epidemiological studies, may be the introduction of phage-typing, based on the finding of lytic phages in this species. We found that two of $10 \mathrm{H}$. pylori strains were lysed by phage HP1 in broth culture. Although HP1 was propagated successfully in liquid cultures of the $H$. pylori acceptor strains, a reproducible plaque assay on solid media (SBA and IBA) could not be established for routine practice. This might be due to inappropriate growth conditions or deficiencies in the expression of phagereceptors under the chosen conditions. For example, the use of the single layer assay instead of the generally preferable double-layer assay for testing phage activity and the induction procedures were necessary because $H$. pylori cells aggregated in soft agar and did not grow in confluent lawns. A successful search for further lytic phages and appropriate growth conditions is the minimum requirement for the construction of a phagetyping system, which could be a worthwhile approach for differentiation of $H$. pylori strains and may provide additional support to the currently available methods of genomic subspecies differentiation.

We thank B. Meister, M. Hemmler-Roloff, A. Spies, M. Chlupka and $\mathrm{B}$. Menge for their technical assistance. 


\section{References}

1. Marshall BJ, Armstrong JA, Francis GJ, Nokes NT, Wee SH Antibacterial action of bismuth in relation to Campylobacter pyloridis colonization and gastritis. Digestion 1987; 37 Suppl 2: 16-30.

2. Goodwin CS, Armstrong JA, Peters M. Microbiology of $C$. pylori. In: Blaser MJ (ed) Campylobacter pylori in gastritis and peptic ulcer disease. New York, Igaku-Shoin Medical Publishers. 1989: 25-49.

3. Schmid EN, von Recklinghausen G, Ansorg R. Bacteriophages in Helicobacter (Campylobacter) pylori). J Med Microbiol 1990; 32: 101-104.

4. Ansorg R, von Recklinghausen G, Pomarius R, Schmid EN Evaluation of techniques for isolation, subcultivation, and preservation of Helicobacter pylori. J Clin Microbiol 1991; 29: 51-53.

5. McNaughton $P$, Matthews REF. Sedimentation of small viruses at very low concentrations. Virology $1971 ; 45$ : 1-9.

6. Kay D. Methods for studying the infectious properties and multiplication of bacteriophage. In: Norris JR, Ribbons DW (eds) Methods in microbiology, vol 7a. London, Academic Press. 1972: 195-197.

7. Bryner JH, Ritchie AE, Foley JW. Techniques for phage typing Campylobacter jejuni. In: Newell DG (ed) Campylobacter, epidemiology, pathogenesis and biochemistry. Lancaster. MTP Press. 1982: 52-56.
8. Maniatis T, Fritsch EF, Sambrook J. Molecular cloning, a laboratory manual. Cold Spring Harbor NY, Cold Spring Harbor Laboratory. 1982: 76-85.

9. Twigg AJ, Sherratt D. Trans-complementable copy-number mutants of plasmid ColE1. Nature 1980; 283: 216-218.

10. Ackermann H-W. Phagentaxonomie 1990. State and problems. BIOforum 1991; 11 : 419-426.

11. Majewski SIH, Goodwin CS. Restriction endonuclease analysis of the genome of Campylobacter pylori with a rapid extraction method: evidence for considerable genomic variation. $J$ Infect Dis 1988; 157: 465-471.

12. Oudbier JH, Langenberg W, Rauws EAJ, Bruin-Mosch C. Genotypical variation of Campylobacter pylori from gastric mucosa. J Clin Microbiol 1990; 28: 559-565.

13. Owen RJ, Bickley J, Lastovica A, Dunn JP, Borman P, Hunton C. Ribosomal RNA gene patterns of Helicobacter pylori from surgical patients with healed and recurrent peptic ulcers. Epidemiol Infect 1992; 108: 39-50.

14. Foxall PA, Hu L-T, Mobley HLT. Use of polymerase chain reaction-amplified Helicobacter pylori urease structural genes for differentiation of isolates. J Clin Microbiol 1992; 30: 739-741.

15. Penfold SS, Lastovic AJ, Elish BG. Demonstration of plasmids in Campylobacter pylori. J Infect Dis 1988; 157: 850-851.

16. Simor AE, Shames B, Drumm B, Sherman P, Low DE, Penner JL. Typing of Campylobacter pylori by bacterial DNA restriction endonuclease analysis and determination of plasmid profile. J Clin Microbiol 1990; 28: 83-86. 